\title{
Expressional Profiling of Telomerase and Telomere-Associated Molecules in the Rat Testis and Seminal Vesicle during Postnatal Developmental Period
}

\author{
Hee Jung Seo ${ }^{1}$, Seong Kyu Lee ${ }^{1}$, Haing Woon Baik ${ }^{1}$, Yong-Pil Cheon ${ }^{2}$, Taehoon Chun ${ }^{3}$, Inho Choi ${ }^{4}$ and Ki-Ho Lee ${ }^{1} *$
}

${ }^{1}$ Department of Biochemistry and Molecular Biology, Eulji University, Daejeon, Korea 301-746, ${ }^{2}$ Department of Biology, Sungshin Women's University, Seoul 136-742, Korea, ${ }^{3}$ School of Life Sciences and Biotechnology, Korea University, Seoul 136-701, Korea, ${ }^{4}$ School of Biotechnology, Yeugnam University and Bovine Genome Resources Bank, Gyeongsan 712-749, Korea

\begin{abstract}
Maintenance of adequate telomere length in developing cells is the most important concern to preserve the integrity of the genome. The length of telomere is strictly regulated by numerous telomere-binding proteins and/or interacting factors. Even though the expression of telomerase in the male reproductive tract has been characterized, developmental expressional profiling of telomerase and other telomere-associated proteins has not been determined in detail. The present study was attempted to examine expression patterns of catalytic subunit(Tert) and RNA component(Terc) of telomerase and two telomerase associated factors, telomerase associated protein $1($ Tepl) and TERF1(TRF1) interacting nuclear factor 2 (Tinf2) in the testis and seminal vesicle of male rat during postnatal development. The real-time PCR analysis was utilized to quantify mRNA expression of molecules. The abundance of Tepl mRNA in the testis and seminal vesicle was the highest at 5 months of age. Expressional fluctuation of Tinf 2 during postnatal development was found in the testis, while expression of Tinf 2 in the seminal vesicle was gradually increased until 5 months of age and then significantly decreased later. mRNA level of Tert gene in the testis was significantly increased at the adult and the elder, while the highest expression of Tert gene in the seminal vesicle was found at 5 months of age. Expression of Terc transcript in the testis and seminal vesicle was the highest at 5 months of age, followed by significant reduction at 1 and 2 years of ages. Such differential gene expression of telomere-associated factors and telomerase components in different male reproductive tissues during postnatal development indicates that maintenance of telomere length would be regulated in tissue- and/or age-specific manners.
\end{abstract}

(Key words : Telomerase, Testis, Seminal vesicle, Development, Telomerase-associated molecule)

\section{INTRODUCTION}

Telomeres are specialized DNA-protein structures which are present at the ends of eukaryotic linear chromosomes and function to protect from chromosomal degradation and fusion, leading cells to apoptosis or growth arrest (Siderakis and Tarsounas, 2007). Telomeric DNA is consisted of tandem G-rich repetitive DNA sequences at which a large number of proteins are bound (Palm and de Lange, 2008). Even though the telomeric DNA sequences do not encode specific proteins, the telomeric repeats are crucial to preserve genome integrity (Bekaert et al., 2004). Interestingly, the number of telomeric repeats among tissues within an organism is not always same, but is dramatically changed during development (Bekaert et al., 2004). In addition, it is well characterized that length of telomere is species- and cell type-specific (Walmsley and Petes, 1985). Thus, it is important to maintain adequate length of telomeric DNA repeats in each tissue and/or cell type.

Based on conventional DNA replication procedure, a portion of telomeric end sequences becomes lost during each round of DNA replication (Bekaert et al., 2004). A specific DNA polymerase, called telomerase, resolves such shortening of telomere length for DNA replication. Telomerase is a complex of two essential components, telomerase reverse transcriptase (TERT), and its RNA component (TERC) (Bekaert et al., 2004). TERT is the catalytic domain of the telomerase, and TERC provides the template for telomere extension. A number of researches have demonstrated a strong relationship between activity of telomerase and protection against telomere erosion during each round of cell replication (Morin, 1989). In most mammalian somatic cells,

* Corresponding author: Ki-Ho Lee, Ph.D. Department of Biochemistry and Molecular Biology and Medical Sciences Research Institute, Eulji University, Daejeon 301-746, Korea. Tel: +82-42-259-1643, Fax: +82-42-259-1649, E-mail: kiholee@eulji. ac.kr 
the activity of telomerase is not sufficient to keep proper length of telomere at each cell division, thus leading into shortening of telomeres throughout postnatal developmental period and eventually cellular quiescence (Flores et al., 2005). However, certain cell types, including germ cell line and cancer cells-possess a relatively high level of telomerase activity during adult life (Bekaert et al., 2004).

Many recent studies have shown the differential patterns of telomerase activity and expression in the gonads of the male and female reproductive tract. In the ovary, the pre-ovulatory oocytes possess a high telomerase activity, while telomerase activity in mature oocytes and cleavage-stage embryos until the 8 cell-embryos become decreased, followed by another significant increase of telomerase activity during progression to morula and blastocyst stages (Eisenhauer et al., 1997; Wright et al., 2001). In the adult testis, no telomerase activity has detected in mature spermatozoa, even though sperms have longer telomeres than those of somatic cells (Eisenhauer et al., 1997; Wright et al., 1996). But, among cell types undergoing spermatogenesis and spermiogenesis, the highest level of TERT mRNA has been found in primary spermatocytes, which are premeiotic cells and undergo DNA replication (Yashima et al., 1998). Other than germ cells, the Sertoli cells possess a high level of TERT mRNA in the adult testis (Yashima et al., 1998). In addition, the telomerase activity in the male reproductive tract is found in prostate and seminal vesicle (Banerjee et al., 1998a and b). Moreover, telomerase-defective mice progressively loss telomeric repeats in germ cells, have increased frequency of cell death, and gradually become infertile (Lee et al., 1998; Chin et al., 1999). Together, these observations indicate that maintenance of telomere length is absolutely essential for keeping male fertility. However, detailed examination of TERT and TERC expression during postnatal development has not been determined.

Numerousfactors are directly and/or indirectly associated with telomere and telomerase to maintain proper telomeric length. Of these factors, telomerase associated protein 1 (TEP1) has been shown to interact with TERC (Harrington et al., 1997) and regulate telomerase activity (Yamada et al., 2000). The presence of TEPI mRNA in the testis has been determined, and it has been speculated that deregulation of TEP1 expression is associated with tumorigenesis (Sugihara et al., 1999). Another well-known telomere-associated factor is TATA-binding protein (TBP)-related factor (TRF1) interacting nuclear factor 2(TINF2). TRF1 is a negative regulator of telomere length maintenance, and TINF2 directly interact with TRF1 and acts as an essential mediator of TRF1 activity in a telomerase-dependent manner(Bianchi et al., 1997; Kim et al., 1999). Others have shown that TINF2 is associated with TRF2 to maintain telomere capping (Kim et al., 2004). In spite of crucial functions of TINF2 for regulation of telomeric length in proliferating cells, the expression of TINF2 in the testis and other tissues of male reproductive tract have not been examined.

Thus, in the present study, we attempted to determine the presence and expressional patterns of Tert, Terc, Tep1, and Tinf2 mRNAs in the testis and seminal vesicle of male reproductive tract during postnatal developmental period by using real-time PCR analysis. In addition, we tried to find out expressional relationship among molecules.

\section{MATERIALS AND METHODS}

\section{Animals and tissue collection}

Pregnant Sprague Dawley female rats and pubertal male rats at 45 days of age were purchased from Samtako (O San, $\mathrm{S}$. Korea) and housed in individual cage under controlled conditions. Water and food were provided for ad libitum consumption for entire experimental period. Prepubertal male rats at 7, 15, and 25 days of ages were obtained from the pregnant female rats. Rats were anesthetized by $\mathrm{CO}_{2}$ stunning, and the testis and seminal vesicle were isolated and quickly frozen in liquid nitrogen. Tissues were stored in $-80^{\circ} \mathrm{C}$ until used for total RNA isolation later. The testes and seminal vesicle of adult male rats at 5 months of age and aged male rats at 1 and 2 years of ages were kindly provided by Aging Tissue Bank (Department of Pharmacology, Pusan National University). Five rats were used for each age group, except 3 rats for 1 and 2 years of age groups.

\section{Total RNA isolation and cDNA generation}

The frozen tissue was grinded in easy-Blue total RNA extract solution (iNtRON Biotech, Sungnam, S. Korea) by using a polytron homogenizer(Fisher Scientific, Pittsburgh, USA). Total RNA was isolated by phenol-chloroform extraction method, and the RNA pellet was resuspended in RNA storage buffer (Ambion, Austin, USA). Total RNA samples were stored in $-80^{\circ} \mathrm{C}$ until used for reverse-transcription (RT) reaction to generate the first strand of cDNA. The 
quantity and quality of total RNA was measured by an UV spectrophotometer (Eppendorf, New York, USA) and agarose gel electrophoresis, respectively. The RT reaction was carried out as stated by the instruction in ImProm-II ${ }^{\mathrm{TM}}$ reverse transcription system (Promega, Madison, USA). One microgram of total RNA was used for each RT reaction. The RT reaction was performed at $25^{\circ} \mathrm{C}$ for $5 \mathrm{~min}, 42^{\circ} \mathrm{C}$ for $1 \mathrm{hr}$, and $70^{\circ} \mathrm{C}$ for $15 \mathrm{~min}$.

\section{Real-time polymerase chain reaction (real-time PCR) analysis}

The real-time PCR was carried out in a mixture of $1 \mu \mathrm{l}$ of cDNA, 10 pmol of each primer, and $10 \mu$ of master mix (Finnzymes, Espoo, Finland). A final volume of the mixture was $20 \mu \mathrm{l}$. The PCR procedure was employed with an initial denaturation step at $95^{\circ} \mathrm{C}$ for $5 \mathrm{~min}$, followed by cycles of denaturation at $95^{\circ} \mathrm{C}$ for $30 \mathrm{sec}$, annealing at $\mathrm{T}_{\mathrm{m}}$ for $30 \mathrm{sec}$, and extension at $72^{\circ} \mathrm{C}$ for $30 \mathrm{sec}$. The final extension at 72 ${ }^{\circ} \mathrm{C}$ for $10 \mathrm{~min}$ was included to produce all PCR products in double-stranded form. The oligonucleotide primers were prepared by using Primer 3 software (http://www.bioneer.co. kr/cgi-bin/primer/pirmer3.cgi: Whitehead Institute/MIT Center for Genomes Research, USA) (Table 1). The sizes of PCR products were confirmed by agarose gel fractionation. In real-time PCR analysis, cyclophilin A (Ppia) was included as an internal PCR control.

\section{Data analysis and presentation}

A mean and a standard error for each age group were obtained from 4-5 repeated analyses of RT and real-time PCR. The expression levels of telomerase and that associated molecules in the testis and seminal vesicle were compared with those of Ppia and presented as relative ratio between target molecule and Ppia. Statistical differences of means among experimental groups for each molecule were determined by one-way ANOVA, followed by a post-hoc analysis, Duncan's test. In all cases, results were considered significant if $p$-values were lower than 0.05 level.

\section{RESULTS}

\section{Expressional Patterns of Telomerase Associated Protein 1(Tep1) in the Testis and Seminal Vesicle during Postnatal Development}

The presence of Tepl mRNA was detected in the testis and seminal vesicle throughout entire postnatal developmental period(Fig. 1). In the testis, the level of Tepl mRNA was significantly decreased and remained in the lowest level at 15,25 , and 45 days of ages, compared with that at 7 days of age (Fig. 1A). However, a transient increase of Tep1 mRNA level was detected at 5 months of age, followed by a significant reduction at 1 year of age (Fig. 1A). A further decrease of Tep1 mRNA abundance was observed at 2 years of age (Fig. 1A). Expressional pattern of Tepl mRNA in the seminal vesicle was different with that in the testis (Fig. 1B). The lowest level of Tepl mRNA was found at 7 days of age. The abundance of Tepl mRNA was gradually but

Table 1. Primer information and PCR condition for real-time PCR

\begin{tabular}{|c|c|c|c|}
\hline $\begin{array}{l}\text { Gene } \\
\text { (GenBank ID) }\end{array}$ & $\begin{array}{l}\text { Primer sequence } \\
\qquad\left(5^{\prime} \rightarrow 3^{\prime}\right)\end{array}$ & $\begin{array}{l}\mathrm{T}_{\mathrm{m}} \\
\left({ }^{\circ} \mathrm{C}\right)\end{array}$ & $\begin{array}{l}\text { PCR product } \\
\text { size (bps) }\end{array}$ \\
\hline $\begin{array}{c}\text { Tep1 } \\
\left(\mathrm{NM} \_022591\right)\end{array}$ & $\begin{array}{l}\text { (F) GACTGCTGGTGGGACAATTT }(5314-5333) \\
\text { (R) CAGCAGCCAGTGATTTGGTA }(5529-5510)\end{array}$ & 56 & 216 \\
\hline $\begin{array}{c}\operatorname{Tinf} 2 \\
\left(\mathrm{NM} \_001006962\right)\end{array}$ & $\begin{array}{l}\text { (F) CAGTTTTTGGAGTCCCTTCG }(360-379) \\
\text { (R) GAAGATTCAGGGCATTGAGG }(510-491)\end{array}$ & 56 & 151 \\
\hline $\begin{array}{l}\text { Terc } \\
\left(\mathrm{NR} \_001567\right)\end{array}$ & $\begin{array}{l}\text { (F) CGCATTCTGGAACCTCAA (111-128) } \\
\text { (R) AGTTCCGTTACTGTCCTTGC (323-304) }\end{array}$ & 53 & 213 \\
\hline $\begin{array}{c}\text { Tert } \\
(\text { NM_053423) }\end{array}$ & $\begin{array}{l}\text { (F) TCAGGCAACAGCTTGAGAGA (1736-1755) } \\
\text { (R) CTGGGTCTGCTTCTTTTTGC (1926-1907) }\end{array}$ & 55 & 191 \\
\hline $\begin{array}{c}\text { Ppia } \\
\text { (NM_017101) }\end{array}$ & $\begin{array}{l}\text { (F) GGCAAATGCTGGACCAAACAC }(342-362) \\
\text { (R) TTAGAGTTGTCCACAGTCGGAGATG (537-513) }\end{array}$ & 59 & 196 \\
\hline
\end{tabular}

Tep1: telomerase associated protein 1; Tinf2 : TERF1 (TRF1) interacting nuclear factor 2; Terc: telomerase RNA component; Tert : telomerase catalytic subunit Ppia : peptidylprolyl isomerase A (cyclophilin A). 


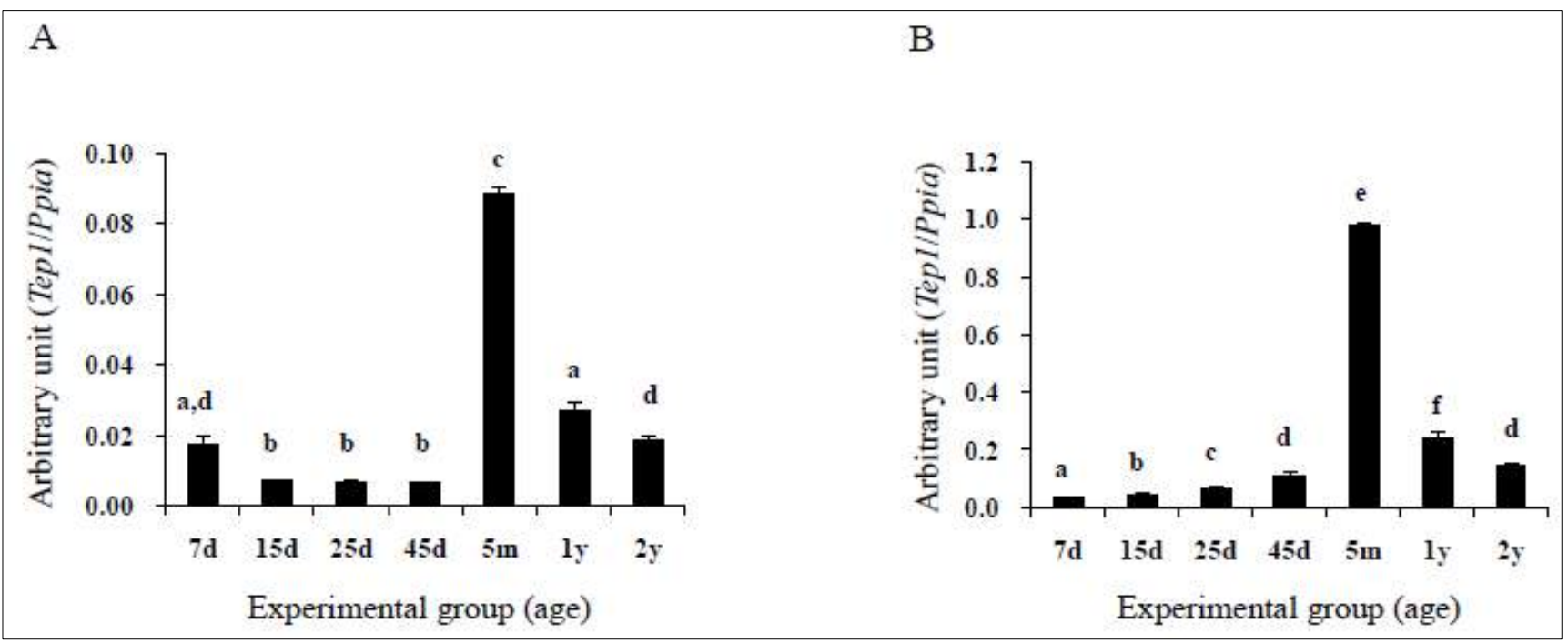

Fig. 1. Expression patterns of Tep1 in the rat testis and seminal vesicle during postnatal period. A) testis and B) seminal vesicle. Different letters in the graphs indicate statistical significance at $p<0.05$. $d$ : day, $m$ : month, and y: year.

significantly increased as animal became aged until 45 days of age (Fig. 1B). A great increase of Tepl mRNA level was detected at 5 months of age, followed by significant decreases at 1 and 2 years of ages (Fig. 1B).

2. Expression of TERF1 (TRF1) Interacting Nuclear Factor 2 (Tinf2) in the Testis and Seminal Vesicle during Postnatal Development

The expression pattern of Tinf 2 mRNA between the testis and seminal vesicle was different, compared with that of Tep1 (Fig. 2). In the testis, significant decreases of Tinf2 mRNA levels were found at 15 and 25 days of ages, compared with Tinf2 mRNA level at 7 days of age (Fig. 2A). However, the level of Tinf 2 mRNA was significantly increased at 45 days of age (Fig. 2A). A further increase of Tinf2 mRNA level was detected at 5 months of age (Fig. 2A). Interestingly, the level of Tinf2 mRNA was significantly decreased at 1 year of age, followed by a drastic increase at 2 years of age (Fig. 2A). The expression pattern of Tinf2
A

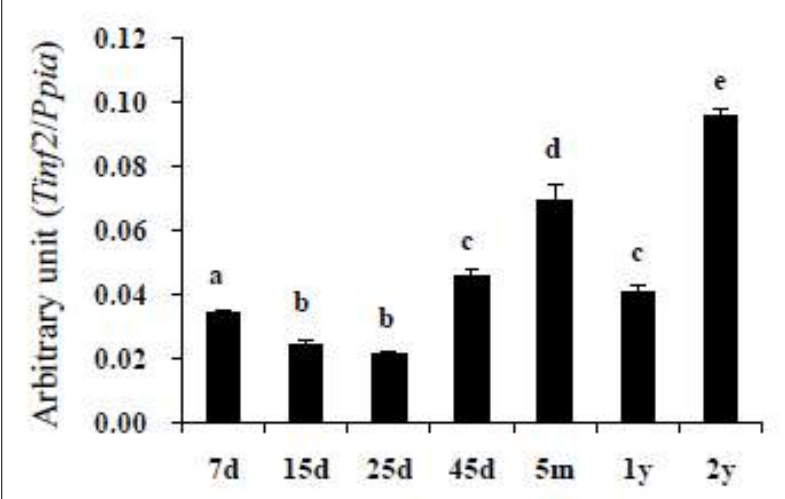

Experimental group (age)
B

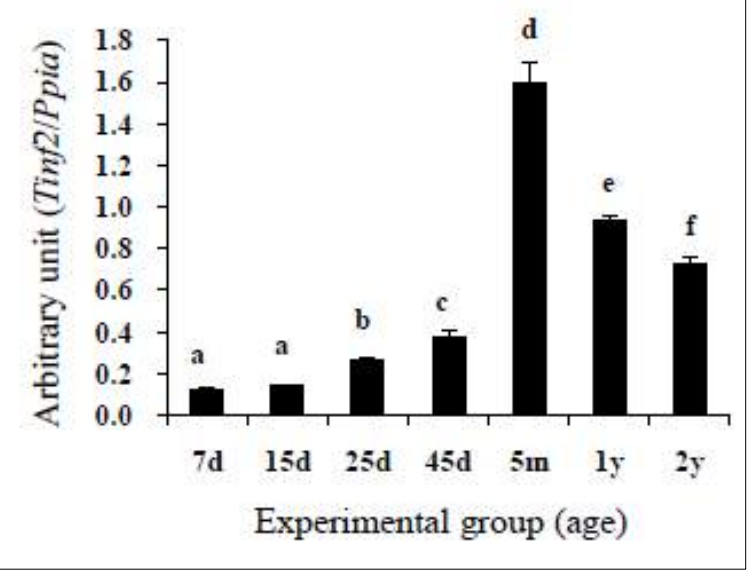

Fig. 2. Expression patterns of Tinf2 in the rat testis and seminal vesicle during postnatal period. A) testis and B) seminal vesicle. Different letters in the graphs indicate statistical significance at $p<0.05$. $d$ : day, $m$ : month, and y: year. 
mRNA in the seminal vesicle was very similar with that of Tep1 mRNA(Fig. 1B and 2B). A minimal expression of Tinf2 mRNA was detected at 7 and 15 days of ages (Fig. 2B). Steady, but significant, increases of Tinf2 mRNA levels were found at 25 and 45 days of ages (Fig. 2B). A dramatic increase of $\operatorname{Tinf} 2$ mRNA abundance was observed at 5 months of age, followed by a significant decrease at 1 year of age (Fig. 2B). The level of Tinf 2 mRNA was further decreased at 2 years of age (Fig. 2B).

\section{Comparison of Telomerase RNA Component} (Terc) Gene Expression in the Testis and Seminal Vesicle at Different Postnatal Ages

Relative abundance of Terc mRNA in the testis and seminal vesicle is shown in Fig. 3. In the testis, a minimal expression of Terc mRNA was detected at 7 days of age (Fig. 3A). However, the level of Terc mRNA was significantly increased at 15 days of age (Fig. 3A). A tremendous increase of Terc mRNA level was seen at 5 months of age, followed by further significant increases at 1 and 2 years of ages (Fig. 3A). Expression pattern of Terc mRNA in the seminal vesicle, however, was different from that of the testis (Fig. 3B). The lowest level of Terc mRNA was detected at 7 days of age, followed by significant increase of the level at 15, 25, and 45 days of ages (Fig. 3B). A further increase of Terc mRNA level was found at 5 months of age (Fig. 3B). A drastic increase of Terc mRNA level was observed at 1 year of age, followed by a significant decline of Terc mRNA abundance at 2 years of age (Fig. 3B).

\section{Expressional Comparison of Telomerase Reverse Transcriptase (Tert) Gene in the Testis and Seminal Vesicle during Postnatal Development}

Expression patterns of Tert mRNA in the testis and seminal vesicle are shown in Fig. 4. A minimal level of Tert mRNA in the testis was detected at 7 days of age (Fig. 4A). The abundance of Tert mRNA was significantly increased at 15 days of age, remaining at the same level until 45 days of age (Fig. 4A). A transient increase of Tert mRNA level was found at 5 months of age (Fig. 4A). However, the level of Tert mRNA was significantly decreased at 1 year of age, followed by a further decrease at 2 years of age (Fig. 4A). Expression pattern of Tert mRNA in the seminal vesicle was very close to that of the testis (Fig. 4B). There was no significant change of Tert mRNA level between 7 and 15 days of ages (Fig. 4B). Significant increases of Tert mRNA abundance was detected at 25 and 45 days of ages, followed by a transient increase of Tert mRNA level at 5 months of age (Fig. 4B). However, the level of Tert mRNA was greatly decreased at 1 year of age (Fig. 4B). A further decrease of Tert mRNA expression was detected at 2 years of age (Fig. 4B).

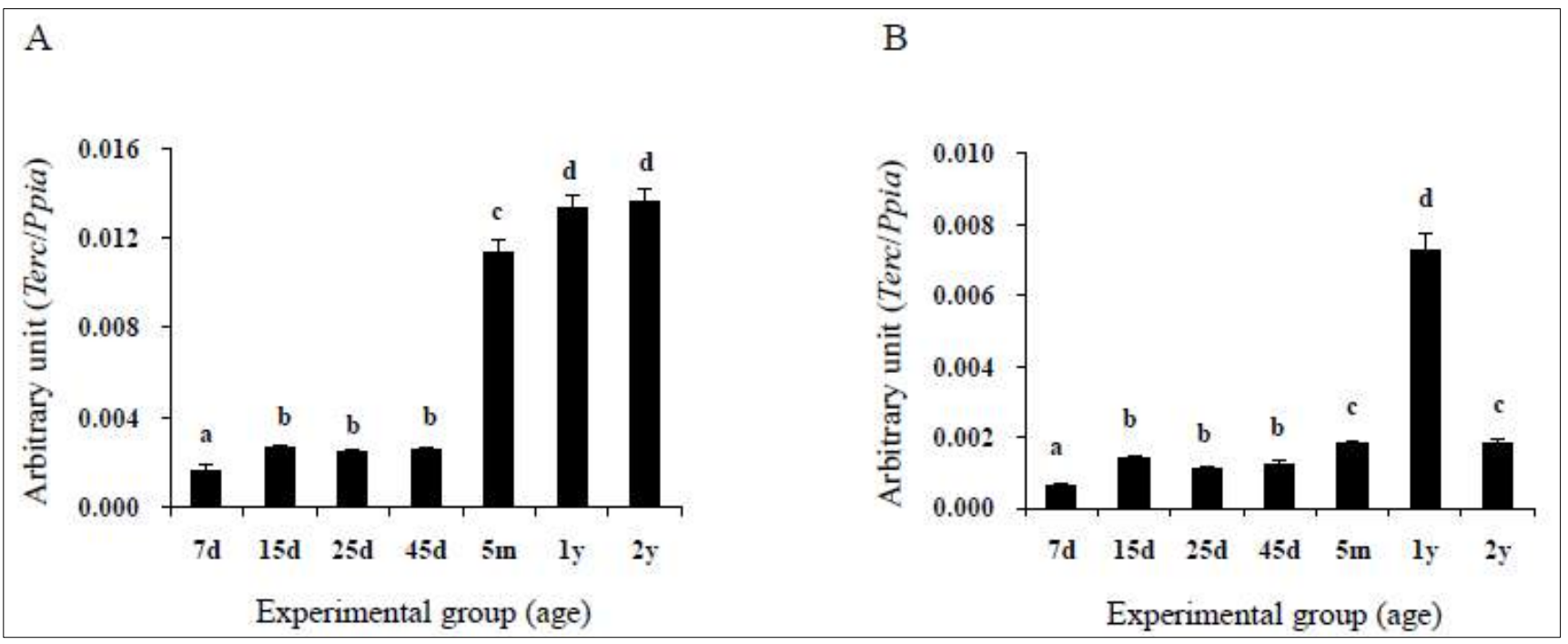

Fig. 3. Expression patterns of Terc in the rat testis and seminal vesicle during postnatal period. A) testis and B) seminal vesicle. Different letters in the graphs indicate statistical significance at $p<0.05$. $d$ : day, $m$ : month, and y: year. 


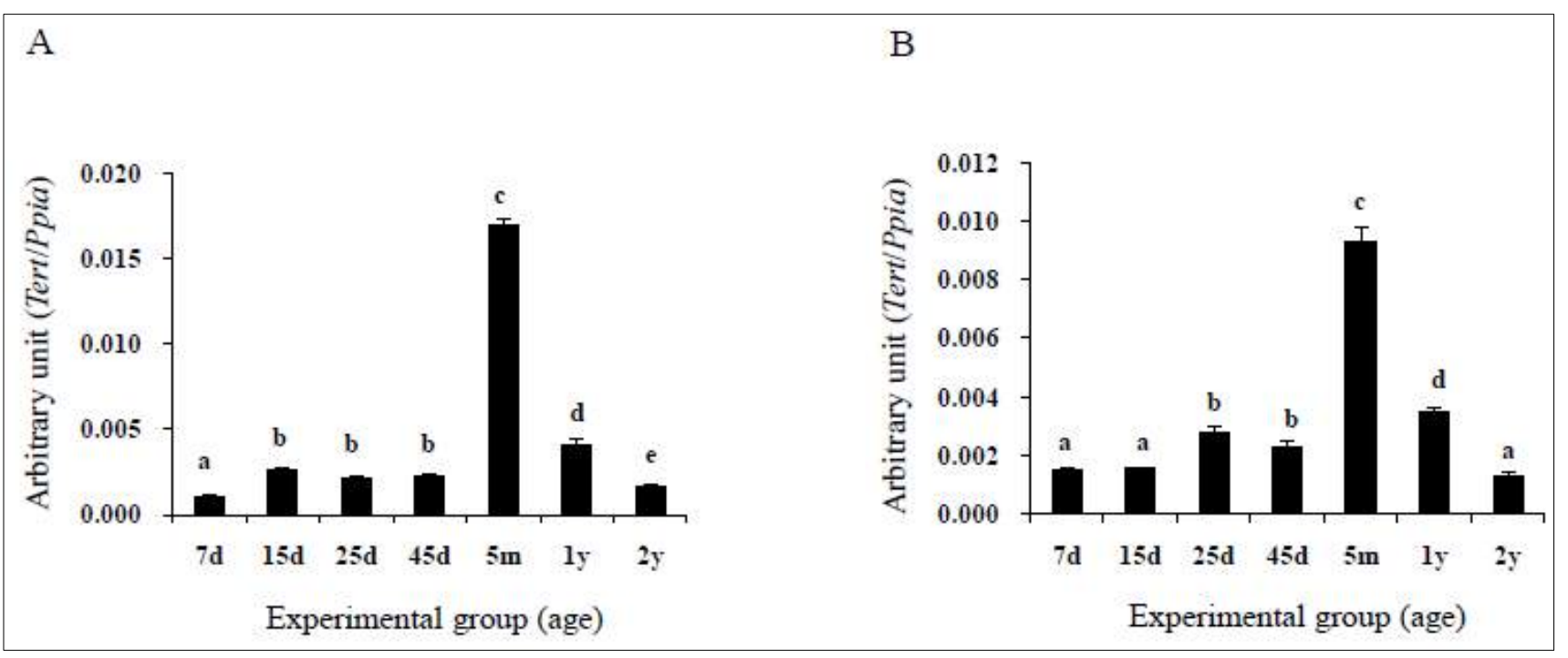

Fig. 4. Expression patterns of Tert in the rat testis and seminal vesicle during postnatal period. A) testis and B) seminal vesicle. Different letters in the graphs indicate statistical significance at $p<0.05$. $d$ : day, $m$ : month, and y: year.

\section{DISCUSSION}

The present study demonstrates differential gene expression of telomerase and telomere-associated factors in the testis and seminal vesicle of the male reproductive tract during postnatal development. Expression patterns of Tepl and Tert mRNAs in the testis and seminal vesicle during postnatal period were somewhat very similar, while expression patterns of Tinf2 and Terc mRNAs were fairly different in the testis and seminal vesicle. Moreover, the current study shows that there is no direct association between gene expression of two telomerase components, Terc and Tert, in the testis or seminal vesicle. Importantly, for the first time, this study reveals the presence of Tinf 2 transcript in the testis and seminal vesicle.

Expression of telomerase subunits in the male reproductive tract has been examined by a number of researches (Banerjee et al., 1998a and b; Weise and Günes, 2009). Weise and Günes (2009) have shown differential expressional patterns of Tert gene in the testis between human and mouse during postnatal development. Expression of TERT in human testis reaches the highest point at the adult, while the highest expression of Tert in mouse testis is detected at early postnatal age(Weise and Günes, 2009). Our present study has demonstrated the highest level of Tert mRNA in rat testis at adult age, which is similar with that in human. These findings suggest that expressional regulation of Tert, at least in the aspect of the testis, would be differentially controlled in species-specific manner. Moreover, tissue-specific regulation of telomerase expression and activity during gestation has been observed in human fetus (Ulaner and Giudice, 1997). The regulation of Tert gene expression in the testis has not been well characterized. Many intrinsic and/or extrinsic factors, including estrogen ( $\mathrm{Li}$ et al., 2010), Ets2 transcription factor (Dwyer and Liu, 2010), and transforming growth factor- $\beta$ (Li and Liu, 2007), are thought to be involved in expression of Tert gene in other tissues. Additional research should be conducted to define regulatory factor(s) of Tert gene in the testis. Other than the testis in the male reproductive tract, the presence of telomerase activityin the prostate and seminal vesicle at postnatal age has been observed (Banerjee et al., 1998a and b). Interestingly, it has been found that prostate and seminal vesicle at adult age have higher telomerase activity than at early postnatal age, indicating the presence of long proliferative life-span stem cells in these tissues (Banerjee et al., 1998a and b). In addition, differential regional distribution of telomerase activity within the tissue has been detected (Banerjee et al., 1998a and b). Together, these observations suggest a highly complicated regulation of Tert gene expression and telomerase activity in the male reproductive tissues during postnatal development.

It is commonly considered that Tert of telomerase is rate limiting component for telomerase activity (Bekaert et al., 2004). However, an increasing body of evidence indicates an important role of Terc gene on telomerase activity. 
Deficiency of Terc gene $\left(\operatorname{Terc}^{-/-}\right)$results in abolishment of telomerase activity, which leads to shortness of telomere, increase of cell apoptosis in the testis, and progressive sterility (Blasco et al., 1997 Chin et al., 1999). These observations imply that Terc mRNA in the telomerase plays a crucial function on regulation of telomerase activity, and thus maintenance of proper telomeric length. Even though it is known that expression of Terc gene in germ cells of the testis is constitutive (Bekaert et al., 2004), the results from the present study show differential expression levels of Terc mRNA in the testis and seminal vesicle during postnatal development. Moreover, Sugihara et al. (1999) demonstrate an increased expression of Terc mRNA in highly proliferating cells. Together, it is believed that not only Tert but also Terc are closely involved in regulation of overall activity of telomerase. Furthermore, to our knowledge, this is the first time to demonstrate differential expression of Terc mRNA in seminal vesicle during postnatal period. It is strongly suggested to determine a relationship between expression of Terc mRNA and development of seminal vesicle after the birth from future researches.

Numerous molecules are associated with telomeric DNA repeats in direct and/or indirect manners to protect the telomere from the shortening. Also, telomerase activity is controlled not only by Terc and Tert but also by telomerase-associated factors (Bekaert et al., 2004 Siderakis and Tarsounas, 2007). In fact, Yamada et al. (2000) have demonstrated a regulation of telomerase activity by Tep 1 through direct interaction with Terc. In normal tissue, expressional levels of Terc and Tepl genes are likely negatively correlated, while there is a positive correlation between Terc and Tep1 mRNA levels in malignant cells (Sugihara et al., 1999). In the present study, there is no clear expressional correlation between Terc and Tepl genes in the testis and seminal vesicle during postnatal development. At the current point, there is no clear answer for explanation of such different observations from our and other's researches. Additional information would be necessary to determine a relationship between Terc and Tepl gene expression. However, the present study reports an apparent evidence of the existence of Tepl mRNA in the seminal vesicle for the first time. A functional role of Tepl in the seminal vesicle should be addressed in future researches.

A mutation of Tinf2 gene results in dyskeratosis congenital, which is a multisystem bone marrow failure syndrome (Walne et al., 2008). The mRNA level of Tinf2 decreased in malignant hematopoietic cells (Yamada et al., 2000). It is recognized that Tinf2 protects telomere from shortening by retaining the integrity of telomeric capping (Bekaert et al., 2004). Despite the crucial role of Tinf2 on maintenance of proper telomeric length, the existence of Tinf2 transcript in the male reproductive tract has not been determined. Data from the current study clearly show expression of Tinf2 gene in the testis and seminal vesicles during postnatal development. Expressional patterns of Tinf2 gene are quietly different between the testis and seminal vesicle, indicating differential regulation of Tinf2 gene expression in tissue-specific manners. Moreover, a fluctuating expressional level of Tinf2 gene in the testis at different postnatal ages implies a complicated regulation of Tinf 2 gene expression. In the seminal vesicle, it is noteworthy that expressional pattern of Tinf 2 gene is relatively similar with those of Tert and Tepl genes. It would be speculated to have existence of close interaction among these 3 molecules to regulate telomere length. Further researches are suggested to examine functional role(s) of Tinf2 in the male reproductive tract.

In conclusion, the present research has shown differential expression of telomerase- and telomere-associated factors in the testis and seminal vesicle during postnatal development. It is suggested that future studies should be focused to reveal regulatory mechanism of gene expression of telomereassociated molecules and of telomerase activity in the male reproductive tract.

\section{ACKNOWLEDGEMENT}

This research was partly supported by Basic Science Research Program through the National Research Foundation of Korea (NRF) funded by the Ministry of Education, Science and Technology (20100016939 and 20100022388) and IPET (Korea Institute of Planning and Evaluation for Technology in Food, Agriculture, Forest and Fisheries), Ministry for Food, Agriculture, Forest and Fisheries, Republic of Korea (108089-03-3-HD130)

\section{REFERENCES}

Banerjee, P. P., Banerjee, S., Zirkin, B. R. and Brown, T. R. 1998a. Lobe-specific telomerase activity in the intact adult Brown Norway rat prostate and its regional distribution within the prostatic ducts. Endocrinology. 139:513-519. 
Banerjee, P. P., Banerjee, S., Zirkin, B. R. and Brown, T. R. 1998b. Telomerase activity in normal adult Brown Norway rat seminal vesicle: regional distribution and age-dependent changes. Endocrinology. 139:1075-1081.

Bekaert, S., Derradji, H. and Baatout, S. 2004. Telomere biology in mammalian germ cells and during development. Dev. Biol. 274:15-30.

Bianchi, A., Smith, S., Chong, L., Elias, P. and de Lange, T. 1997. TRF1 is a dimer and bends telomeric DNA. EMBO J. 16:1785-1794

Blasco, M. A., Lee, H.-W., Hande, M. P., Samper, E., Lansdorp, P. M., DePinho, R. A. and Greider, C. W. 1997. Telomere shortening and tumor formation by mouse cells lacking telomerase RNA. Cell. 91:25-34.

Chin, L., Artandi, S. E., Shen, Q., Tam, A., Lee, S. L., Gottlieb, G. J., Greider, C. W. and DePinho, R. A. 1999. p53 deficiency rescues the adverse effects of telomere loss and cooperates with telomere dysfunction to accelerate carcinogenesis. Cell. 97:527-538.

Dwyer, J. M. and Liu, J. P. 2010. Ets2 transcription factor, telomerase activity and breast cancer. Clin. Exp. Pharmacol. Physiol. 37:83-87.

Eisenhauer, K. M., Gerstein, R. M., Chiu, C., Conti, M. and Hsueh, A. J. W. 1997. Telomerase activity in female and male rat germ cells undergoing meiosis and in early embryos. Biol. Reprod. 56:1120-1125.

Flores, J. M., Cayuela, M. L. and Blasco, M. A. 2005. Effects of telomerase and telomere length on epidermal stem cell behavior. Science. 309:1253-1256.

Harrington, L., McPhail, T., Mar, V., Zhou, W., Oulton, R., Amgen EST program, Bass, M. B., Arruda, I. and Robinson, M. O. 1997. A mammalian telomerase-associated protein. Science. 275:973-977.

Kim, S. H., Beausejour, C., Davalos, A. R., Kaminker, P., Heo, S. J. and Campisi, J. 2004. TIN2 mediates functions of TRF2 at human telomeres. J. Biol. Chem. 279:43799-43804.

Kim, S. H., Kaminker, P. and Campisi, J. 1999. TIN2, a new regulator of telomere length in human cells. Nat. Genet. 23:405-412.

Lee, H. W., Blasco, M. A., Gottlieb, G. J., Horner, J. W., Greider, C. W. and DePinho, R. A. 1998. Essential role of mouse telomerase in highly proliferative organs. Nature. 392:569-574.

Li, H. and Liu, J. P. 2007. Mechanisms of action of TGF-beta in cancer: evidence for Smad3 as a repressor of the hTERT Li, H. Simpson, E. R. and Liu, J. P. 2010. Oestrogen, telomerase, ovarian ageing and cancer. Clin. Exp. Pharmacol. Physiol.
37:78-82.

Morin, G. B. 1989. The human telomere terminal transferase enzyme is a ribonucleoprotein that synthesizes TTAGGG repeats. Cell. 59:521-529.

Palm, W. and de Lange, T. 2008. How shelterin protects mammalian telomeres. Annu. Rev. Genet. 42:301-334.

Siderakis, M. and Tarsounas, M. 2007. Telomere regulation and function during meiosis. Chromosome Res. 15:667-679.

Sugihara, M., Ohshima, K., Nakamura, H., Suzumiya, J., Nakayama, Y., Kanda, M., Haraoka, S. and Kikuchi, M. 1999. Decreased expression of telomerase-associated RNAs in the proliferation of stem cells in comparison with continuous expression in malignant tumors. Int. J. Oncol. 15:1075-1080.

Ulaner, G. A. and Giudice, L. C. 1997. Developmental regulation of telomerase activity in human fetal tissues during gestation. Mol. Hum. Reprod. 3:769-773.

Walmsley, R. M. and Petes, T. D. 1985. Genetic control of chromosome length in yeast. Proc. Natl. Acad. Sci. U. S. A. 82:506-510.

Walne, A. J., Vulliamy, T., Beswick, R., Kirwan, M. and Dokal, I. 2008. TINF2 mutations result invery short telomeres: analysis of a large cohort of patients with dyskeratosis congenital and related bone marrow failure syndromes. Blood. 112:3594-3600

Weise, J. M. and Günes, C. 2009. Differential regulation of human and mouse telomerase reverse transcriptase (TEFT) promoter activity during testis development. Mol. Reprod. Dev. 76:309317.

Wright, D. L., Jones, E. L., Mayer, J. F., Oehninger, S., Gibbons, W. E. and Lanzendorf, S. E. 2001. Characterization of telomerase activity in the human oocyte and preimplantation embryo. Mol. Hum. Reprod. 7:947-955.

Wright, W. E., Piatyszek, M. A., Rainey, W. E., Byrd, W. and Shay, J. W. 1996. Telomerase activity in human germline and embryonic tissues and cells. Dev. Genet. 18:173-179.

Yamada, K., Yajima, T., Yagihashi, A., Kobayashi, D., Koyanagi, Y., Asanuma, K., Yamada, M., Kameshima, H. and Watanabe, N. 2000. Role of human telomerase reverse transcriptase and telomeric-repeat binding factor protein 1 and 2 in human hematopoietic cells. Jpn. J. Cancer Res. 91:1278-1284.

Yashima, K., Maitra, A., Rogers, B. B., Timmons, C. F., Rathi, A., Pinar, H., Wright, W. E. and Gazhar, A. F. 1998. Expression of the RNA component of telomerase during human development and differentiation. Cell Growth Differ. 9:805-813.

(Received May 13, 2011; Revised Jun. 5, 2011; Accepted Jun. 12, 2011) 